\title{
Tests of disinfection by heat in a bedpan washing machine
}

\author{
G. A. J. AYliffe, B. J. COLlins, AND C. E. A. DEVERILL
}

From the Hospital Infection Research Laboratory, Summerfield Hospital, Birmingham

SYNOPSIS Tests of effectiveness of disinfection of metal and polypropylene bedpans were made in a washer fitted with a steam generator. Broth cultures of Escherichia coli, Pseudomonas aeruginosa, Staphylococcus aureus, or Streptococcus faecalis (approximately $4 \times 10^{8}$ organisms) were sealed in lengths of capillary tubing and attached to the surface of the pans. In other tests, pans were contaminated with an artificial soil containing $S t r$. faecalis $\left(10^{8}\right.$ organisms $\left./ \mathrm{ml}\right)$. In both series of tests, counts of surviving organisms were made at the end of the washing and disinfection cycle. The tests using capillary tubes showed that the Gram-negative bacilli were effectively killed, but not necessarily Gram-positive cocci. However, when incorporated in standard soil, Str. faecalis was killed or removed during the cycle.

The results indicate that the disinfection process was effective for metal bedpans, but less so for polypropylene. Possible disadvantages and modification of the machine are suggested.

Non-disposable bedpans are commonly disinfected in washing machines by means of hot water or steam. Steam is usually supplied from a central source, but in new hospitals this is often no longer available in most of the wards and alternative methods are required. Disposable bedpan systems may be used, but the destructors can be used only when the drainage system is appropriate, and they have deficiencies that may be an infection hazard. However, these deficiencies may be considerably reduced by simple modifications and the use of completely disposable pans so that holders are no longer required (Gibson 1973a and b). Nondisposable bedpans may still be preferred and a machine with an electrically heated steam generator for disinfection is available.

Tests of bactericidal efficiency are difficult to interpret on machines which involve washing as well as disinfection. The evaluation of a new method (Niléhn, 1972) in which the effects of washing are excluded is reported in this paper. In the test, suspensions of organisms are sealed in lengths of heat-stable polythene tubing and applied to the surface of the bedpan. The reduction in numbers of viable organisms after completion of the cycle may be used as an indication of the efficiency of disinfection of the machine. Cleaning efficiency is also an important requirement in a washing machine, and additional tests to assess this property in a bedpan washer with a steam generator are described here.

Received for publication 19 June 1974.

\section{Methods}

Tests were made in the laboratory on a Dent and Hellyer bedpan washer/disinfector (B55 SG). This is a standard model fitted with an atmospheric steam generator (see fig) for use where main steam is not available. The cycle includes a cold-water wash of 20 seconds, a hot-water wash of 15 seconds, and a steam process of 115 seconds with the option of a final rinse of eight seconds. The generator is filled

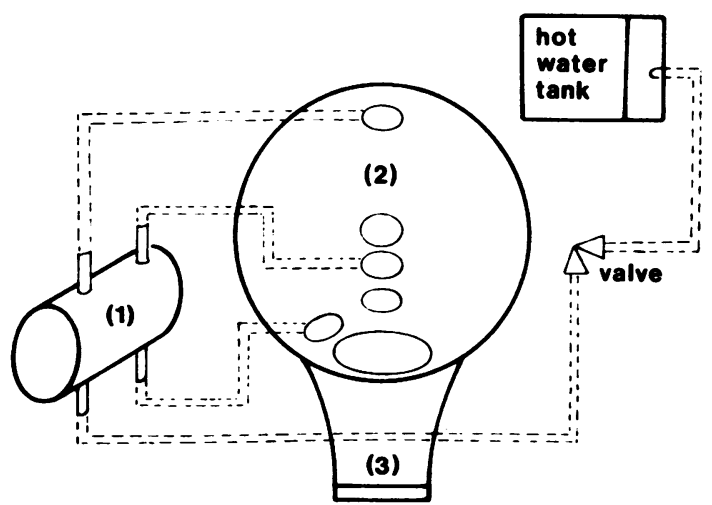

(1) Steam generator

(2) Chamber of washer

(3) Drain

Fig. A bedpan washer with steam supply. 
from the hot water tank at the start of the hotwater wash and steam is produced by heating the water with an electric coil. Steam is introduced into the bowl through two pipes from the top of the generator. A modification included in the test machine is a temperature probe in the chamber which operates a green light on the control panel at the end of the cycle if a temperature of $80^{\circ} \mathrm{C}$ is reached. Tests were made with polypropylene and stainless steel bedpans, and the reliability of the probe and the green light as an indication of adequate disinfection was assessed.

\section{Bacteriology}

ORGANISMS

Organisms used in the tests were Pseudomonas aeruginosa NCTC 6749; Escherichia coli NCTC 8196; Staphylococcus aureus NCTC 9717; and Streptococcus faecalis (KR).

\section{POLYTHENE CAPILLARY TUBE TESTS}

The test organisms were grown on plates containing nutrient agar and $10 \%$ horse blood for 18 hours and washed off into $10 \mathrm{ml}$ nutrient broth (Oxoid no. 2). After thorough mixing, $0.1 \mathrm{ml}$ of the suspension was injected with a sterile syringe into heat-resistant polythene capillary tubing (Portex) of length $130 \mathrm{~mm}$ and internal diameter $1.4 \mathrm{~mm}$. The filled capillaries were heat sealed and attached to the bedpan by means of autoclave tape in the following sites: (1) the internal surface of the base; (2) the external surface of the seat; and (3) under the rim. Thermocouples were also attached to three adjacent sites on the pan. After completion of the disinfection process the organisms were washed from the polythene tubing into $10 \mathrm{ml}$ of nutrient broth and viable counts of the survivors were made. The nutrient broth was also incubated at $37^{\circ}$ for 48 hours and subcultured. Similar control counts were made of organisms in untreated capillary tubes. Twenty-five stainless steel and 26 polypropylene bedpans were tested with one or more organisms. The probe reached the required temperature of $80^{\circ} \mathrm{C}$ in 35 of the cycles; in the other 16 cycles, cold water was deliberately introduced into the steam generator so that the probe did not reach $80^{\circ} \mathrm{C}$ during the cycle.

\section{CLEANING AND DISINFECTION}

A suspension of Str. faecalis was added to standard soil (BS 2745, 1966) to give approximately $10^{7}$ organisms $/ \mathrm{ml}$. The standard soil was a mixture of $10 \mathrm{ml}$ of serum, $6 \mathrm{~g}$ of dried milk powder, and $1 \mathrm{ml}$ of $1 \%$ nigrosine. The mixture was spread over the internal surface and seat area of the bedpan and allowed to dry at room temperature for one hour. Areas of approximately $50 \mathrm{sq} \mathrm{cm}$ from each of these sites were sampled with a moist cotton wool swab before and after treatment in the machine. Swabs were cultured on $10 \%$ blood agar and incubated at $37^{\circ} \mathrm{C}$ for 18 hours. Tests were made with three stainless steel and one polypropylene bedpans. Other tests were made with eight stainless steel and six polypropylene bedpans coated with a similar suspension of Str. faecalis in a $1 \%$ solution (Mostafa and Chackett, in preparation).

\section{Results}

Table I shows the overall results of the polythene capillary tube tests when the probe in the chamber reached $80^{\circ} \mathrm{C}$ during the cycle. Since cultures from many of the tubes after heating showed no growth the highest viable count of each organism and the number of tubes showing no growth are reported rather than the mean count. Gram-negative bacilli were effectively killed by the heat treatment in the machine. In 21 tests with $E$. coli, growth occurred after treatment in two tubes only, one of which showed growth in the broth only, ie, less than $10^{2}$ organisms; $1 / 30$ tests with $P$ s. aeruginosa showed more than $10^{2}$ organisms after treatment. However, only 1/33 tests with Str. faecalis and 9/30 with Staph. aureus showed no growth, although a reduction of at least $10^{4}(99.99 \%)$ was obtained with all metal bedpans. Results with plastic bedpans were less good.

\begin{tabular}{|c|c|c|c|}
\hline Organism & Type of Pan & $\begin{array}{l}\text { Number of Tests Showing No } \\
\text { Growth after Treatment }\end{array}$ & $\begin{array}{l}\text { Highest Count of Surviving } \\
\text { Organisms }\end{array}$ \\
\hline Staph. aureus & $\begin{array}{l}\text { Stainless steel } \\
\text { Polypropylene }\end{array}$ & $\begin{array}{l}9 / 18 \\
0 / 12\end{array}$ & $\begin{array}{l}3 \times 10^{2} \\
3.8 \times 10^{4}\end{array}$ \\
\hline Str. faecalis & $\begin{array}{l}\text { Stainless steel } \\
\text { Polypropylene }\end{array}$ & $\begin{array}{l}1 / 15 \\
0 / 18\end{array}$ & $\begin{array}{l}4.3 \times 10^{4} \\
4.5 \times 10^{6}\end{array}$ \\
\hline E. coli & $\begin{array}{l}\text { Stainless steel } \\
\text { Polypropylene }\end{array}$ & $\begin{array}{r}11 / 12 \\
8 / 9\end{array}$ & $\begin{array}{r}3 \times 10^{2} \\
<10^{2}\end{array}$ \\
\hline Ps. aeruginosa & $\begin{array}{l}\text { Stainless steel } \\
\text { Polypropylene }\end{array}$ & $\begin{array}{l}12 / 12 \\
13 / 18^{2}\end{array}$ & $\begin{array}{l}0 \\
5 \cdot 2 \times 10^{4}\end{array}$ \\
\hline
\end{tabular}

Table I Reduction of organisms in polythene capillary tubing after steam disinfection of bedpans ${ }^{1}$

${ }^{1}$ Mean control counts $4.5 \times 10^{8}$

'Four other tests showed $<10^{2}$ organisms. 
Table II Mean temperature and reduction of organisms in polythene capillary tubing at various sites of bedpan after steam disinfection ${ }^{1}$

${ }^{1}$ Mean control counts $4.8 \times 10^{8}$ organisms

${ }^{2}$ Sites: 1 Internal surface of the base

2 External surface of seat

3 Under the rim

Table II shows the mean temperatures reached on different sites on the bedpan and the corresponding reduction of Staph. aureus and Str. faecalis in polythene capillary tubes attached to adjacent sites. The mean temperature was lowest on the outside of the pans, and was below $80^{\circ} \mathrm{C}$ on plastic pans. These results confirm that disinfection was less effective with plastic pans; the highest count in the tests $\left(4.5 \times 10^{6}\right)$ was on the outer surface of a polypropylene bedpan after completion of an apparently adequate steam cycle. In similar tests on bedpans when the probe failed to reach $80^{\circ} \mathrm{C}$, growth occurred from all tubes including $E$. coli and Ps. aeruginosa. Total counts were much higher, although a satisfactory reduction in counts was often obtained in tubes attached to internal surfaces.

After washing and disinfecting in the machine, no Str. faecalis was grown from metal or plastic bedpans coated with the standard soil or albumen solution. Growth was obtained from all pans inadequately treated, ie, in which the probe failed to reach $80^{\circ} \mathrm{C}$ although there was a substantial reduction in numbers of surviving organisms. Results of the tests for cleaning of pans coated with the standard soil varied and depended on how long the pans were dried before washing. If pans were washed immediately after coating, cleaning was satisfactory, but if dried for some hours residual soil remained on the seat and under the rim. Soil was more effectively removed from metal than from polypropylene pans. No organisms were isolated from residual soil on the steel or polypropylene pans after a satisfactory cycle in the machine.

\section{Discussion}

Bacteriological tests for efficiency of sterilization by heat are readily available if required, eg, spore strips, but a reproducible bacteriological test for heat disinfection of equipment has long been required. The test using polythene capillary tubing described by Dr Niléhn enables a reduction in numbers of organisms caused by heat and not by the washing process to be measured. The use of tubing increases the severity of the test, and the additional penetration of heat required ensures a safety margin corresponding to organisms protected by organic matter. The test is also flexible; a range of different organisms varying in numbers and in resistance to heat can be used, and more than one surface of a bedpan can be tested at the same time. Nevertheless, cleaning is an important prerequisite to effective disinfection and additional tests with contaminate natural or artificial soil are also required.

Since it was suggested by the manufacturers of the bedpan washer that adequate disinfection should be obtained if a probe in the chamber reached $80^{\circ} \mathrm{C}$, the tests for efficiency of the bedpan disinfector were based on this temperature as indicated by a green light on the panel. The bacteriological tests demonstrated that the steam cycle was adequate under most circumstances and that the probe is a reliable indicator of disinfection of metal pans. Heat penetration of plastic pans was less good and the interpretation of tests was more difficult. Although the results indicate that polypropylene pans are more difficult to disinfect reliably in this machine, the tests made were particularly stringent. A higher temperature in the chamber or a longer exposure time may be required for plastic pans although tests with soil (B.S. soil contaminated with Str. faecalis) suggested that if the process included washing, disinfection of both plastic and metal pans was satisfactory. This view of metal pans was also supported by Dr Keith Rogers in tests on six bedpans inoculated with a suspension of organisms in faeces.

Str. faecalis and, to a lesser extent, Staph. aureus were more resistant to heat than Gram-negative bacilli, but Str. faecalis is not an intestinal pathogen. Although Staph. aureus is rarely a cause of intestinal infection it is an important cause of cross infection and should be removed or killed on the seat area of 
the bedpan. The proposed tests include both heatresistant and heat-sensitive vegetative organisms. Spores were not included since they are not relevant to intestinal infection, and killing of spores is not generally required in a disinfection process. Viruses are variable in their response to heat and bacteriophage was found to be moderately resistant (Niléhn, 1972). Since the heat resistance of Str. faecalis was similar to that of bacteriophage, a virus was not included in these tests but further tests with viruses may be necessary in the future. It is suggested that the following tests would be suitable for commissioning machines:

\section{STANDARD SOIL TEST}

Standard (BS 2745) soil mixed with Str. faecalis $\left(10^{7}\right.$ organisms $/ \mathrm{ml}$ ) is applied to the bedpan and dried for one hour before processing. After a satisfactory cycle, viable organisms should not be recovered on direct plating of blood agar from the base, under the rim, or from any visible soil remaining after washing.

\section{TESTS ON INTERNAL SURFACE}

Suspensions of Staph. aureus and E. coli sealed in polythene tubes should be applied to the internal surface and base of the pan. No $E$. coli should be isolated on direct plating, or at least a reduction of $10^{6}(99.9999 \%)$ viable organisms should be obtained. The extent of reduction of Staph. aureus required is more difficult to assess, but a reduction of at least $10^{4}(99.99 \%)$ on the seat area should be obtained.

\section{TESTS WITH DRIED FAECES}

Tests with dried faeces contaminated with known numbers of Str. faecalis and Staph. aureus may also be used to confirm test 1 (Rogers, personal communication).

The assessment of the cleaning process is also difficult owing to problems of standardization of the application of soil. The British Standard, B.S. 2745, describes the soil, but not how much should be applied and how long it should be left before washing. If the bedpan is washed immediately after application, the soil is readily removed but if left overnight removal is difficult. In the tests described here it was decided to allow the pan to dry for one hour after application of the soil. Further work on measurement of cleaning efficiency using radioactive labelled albumen is proceeding and will be published later (Mostafa and Chackett, in preparation). The washing process did not always adequately clean the seat area or under the rim, although disinfection was effective. Some attempt to improve the washing process and modify existing bedpans should be considered by manufacturers.

The washer operates satisfactorily provided the hot water supply system is maintained at $50^{\circ} \mathrm{C}$ or above as recommended by the manufacturer. When water below this temperature was introduced under test conditions, the probe failed to reach the required temperature by the end of the cycle. This could occur in use when several pans are washed in quick succession and the temperature of the central hot water supply is below $50^{\circ} \mathrm{C}$. To overcome these possible difficulties it is suggested that an additional indicator light operating when the water in the tank is above $50^{\circ} \mathrm{C}$ could be fitted to the machine. A cycle would not be started unless this light was showing. Since the failure of other systems may also prevent the completion of a satisfactory cycle it may be preferred to fit an additional light indicating a 'faulty' cycle.

Since bedpan washers are expensive, the problem of whether routine disinfection of bedpans in hospital wards is necessary at all is worth consideration. In a 900-bedded acute general hospital where many bedpan washing machines are not fitted with a steam disinfection process, 20 initially undiagnosed cases of Salmonella infection were admitted to adult wards over a two-year period and there was no spread of infection. The risks of cross infection by this route may, therefore, be small but they cannot be discounted. If non-disposable systems are installed in new hospitals it would seem reasonable to use washers with a heat disinfection process. The problem of whether to install disposable systems or washer-disinfectors is difficult and has been considered elsewhere (British Medical Journal, 1974). It seems reasonable that washer-disinfectors should be installed at least in paediatric, maternity, and infectious disease units. In these areas, existing washers of the basic type described should be modified, if necessary, either by fitting a steam generator or with a mechanism for controlling the steam process to ensure disinfection. Elsewhere the choice between a system using completely disposable bedpans with a safe disposal machine and washerdisinfectors cannot be made on bacteriological grounds alone, but should be made in collaboration with engineers and nursing staff.

We wish to thank Dr Keith Rogers and Dr G. Mostafa for their collaboration and Dent and Hellyer Limited for the loan of a bedpan washer and for their cooperation.

\section{References}

British Medical Journal (1974). Leading article. Tomorrow's bedpans. Brit. med. J., 1, 298-299.

Gibson, G. L. (1973a). Bacteriological hazards of disposable bedpan systems. J. clin. Path., 26, 146-153.

Gibson, G. L. (1973b). A disposable bedpan system using an improved disposal unit and self-supporting bedpans. J. clin. Path., 26, 925-928.

Niléhn, B. (1972). A method for the quantitative microbiological check of heat decontaminators. Scand. J. infect. Dis., 4, 245253. 